\title{
Rare Case of Surviving Infant with Strawberry Yoghurt like Blood Diagnosed to Be Infantile Hypertriglyceridemia at 1 Month Old: A Case Report
}

\author{
Matei Mselle1,2*, Aisa Shayo1,2, Ronald Mbwasi1,2, Faith Mosha',2, Jeremia Pyuza3, \\ Philip Mrindoko1,2, Nyemo Peter1,2, Elton Meleki'2, Elise Kimambo1,2, Arnold Likiliwike1,2, \\ Lucy Frisch1, Magreth Swai' ${ }^{1}$, Zaituni Hatibu1 ${ }^{1}$, Ally Iman',2, Beatrice Maringo², Linda Kissila², \\ Ikupa Minga', Deborah Mchaile ${ }^{1,2}$

\footnotetext{
${ }^{1}$ Department of Paediatrics and Child Health, Kilimanjaro Christian Medical University College, Moshi, Tanzania ${ }^{2}$ Department of Paediatrics and Child Health, Kilimanjaro Christian Medical Centre, Moshi, Tanzania

${ }^{3}$ Department of Clinical Laboratory, Kilimanjaro Christian Medical Centre, Moshi, Tanzania

Email: *mathewmselle90@gmail.com, philipmrindoko1@gmail.com, ellierolland@gmail.com, elisekimambo@gmail.com, drfaithmosha@gmail.com, arnolddav23@gmail.com, pyuzaraymond@gmail.com, aisa.shayo@gmail.com, ronald.mbwasi@gmail.com, deborahsia@hotmail.co.uk, zaitunihatibu.zh@gmail.com, lindakissila5@gmail.com, iminga2003@gmail.com,nyemopk@gmail.com, allyiman05@gmail.com,lucyfrisch@yahoo.com,maggyjossy@gmail.com
}

How to cite this paper: Mselle, M., Shayo, A., Mbwasi, R., Mosha, F., Pyuza, J., Mrindoko, P., Peter, N., Meleki, E., Kimambo, E., Likiliwike, A., Frisch, L., Swai, M., Hatibu, Z., Iman, A., Maringo, B., Kissila, L., Minga, I. and Mchaile, D. (2021) Rare Case of Surviving Infant with Strawberry Yoghurt like Blood Diagnosed to Be Infantile Hypertriglyceridemia at 1 Month Old: A Case Report. Open Journal of Pediatrics, 11, 777-785.

https://doi.org/10.4236/ojped.2021.114072

Received: September 17, 2021

Accepted: December 12, 2021

Published: December 15, 2021

Copyright $\odot 2021$ by author(s) and Scientific Research Publishing Inc. This work is licensed under the Creative Commons Attribution International License (CC BY 4.0).

http://creativecommons.org/licenses/by/4.0/ (c) (i) Open Access

\begin{abstract}
Background: Hypertriglyceridemia in children means increased plasma fasting Triglyceride levels above the $95^{\text {th }}$ percentile for age and sex. For children aged 0 to 9 years, a triglyceride level greater than or equal to $100 \mathrm{mg} / \mathrm{dl}$ is considered above the $95^{\text {th }}$ percentile. Hypertriglyceridemia can be mild to borderline high, moderate to high, very high, severe and very severe $(>2000$ $\mathrm{mg} / \mathrm{dl}$ ). We present the case of a 1 month and 3 weeks old baby who presented with difficulty in breathing. It was accidentally found to have strawberry yoghurt like blood during phlebotomy, of which upon investigation had very high triglyceride levels of $>2000 \mathrm{mg} / \mathrm{dl}$. Case Presentation: 1 month and 3 weeks old female baby, admitted as referral from nearby health centre presenting with difficulty in breath, her blood sample was incidentally found to appear as strawberry yoghurt like. Clinically the infant had features suggestive of respiratory distress, with no other systemic abnormalities noted. Chest $\mathrm{X}$-ray that was done had features of pneumonia. The working diagnosis on admission was Pneumonia, Electrolyte imbalance. The strawberry yoghurt like blood raised suspicions of hypertriglyceridemia. Our triglyceride levels in the infant were very high at $136 \mathrm{mmol} / \mathrm{l}(12,046 \mathrm{mg} / \mathrm{dl})$. The patient was treated with IV antibiotics for pneumonia, electrolytes were corrected and Rosuvastatin was started. This patient improved remarkably and was dis-
\end{abstract}


charged with Rosuvastatin. Lipid profile was followed up for 4 consecutive months in our outpatient clinic with a drastic drop in triglyceride and cholesterol. Conclusion: We report a case of infantile hypertriglyceridemia found accidentally during phlebotomy. Despite limited resource to evaluate further on primary cause of this condition as well as family's poor economic status to seek further medical evaluation outside the country, this case report raises awareness on how to deal with this condition in a low resource setting. It also highlights the role of statins in the treatment of hypertriglyceridemia.

\section{Keywords}

Strawberry Yoghurt Like Blood, Hypertriglyceridemia, Tanzania

\section{Background}

Severe hypertriglyceridemia can be potentially fatal condition that can have primary and secondary causes. Triglyceride levels above the $95^{\text {th }}$ percentile for age and sex define hypertriglyceridemia [1] [2] [3] [4]. Hypertriglyceridemia can be mild to borderline high (150 - $199 \mathrm{mg} / \mathrm{dl})$, moderate to high $(200-499 \mathrm{mg} / \mathrm{dl})$, very high (500 - $999 \mathrm{mg} / \mathrm{dl})$, severe (1000 - $1999 \mathrm{mg} / \mathrm{dl})$ and very severe (>2000 $\mathrm{mg} / \mathrm{dl}$ ) [5] [6] [7] [8] Primary hypertriglyceridemia is due to a genetic defect. Secondary hypertriglyceridemia in children can be associated with kidney disease, endocrine disorder, immunological disorder, lifestyle (e.g. eating high-fat diet) and medication [9]. Prevalence of hypertriglyceridemia in infants is quite limited more specifically in developing countries, however, in developed countries like in United States (US), approximately 20 percent of children (age 6 to 19 years) have adverse levels of one or more lipid values, of which 10.2 percent have elevated TG of ( $\geq 130 \mathrm{mg} / \mathrm{dl}$ [1.5 mmol/l]) [10]. Hypertriglyceridemia if remain undiagnosed and treated can result in pancreatitis, lipemia retinal, coronary heart disease and death [11] [12]. Management is still challenging in underdeveloped countries due to the interplay of genetic and secondary causes as well as the lack of evidence-based guidelines [11]. Therefore treatment primarily focuses on promoting healthy eating habits and encouraging weight loss for those who are obese rather than treating the triglyceride (TG) value per se. In infants, lifestyle modification can be hard to implement, therefore prompt medical intervention is the choice of treatment. Otherwise severely elevated TG levels (i.e., a single TG level $>2000 \mathrm{mg} / \mathrm{dl}$ ) or persistent Triglyceride levels $>500 \mathrm{mg} / \mathrm{dl}$ (5.6 $\mathrm{mmol} / \mathrm{l}$ ) can lead to complication and therefore pharmacologic treatment in this setting may be warranted to prevent these complications.

Here we present a case of 1 month and 3 weeks old baby with skinny strawberry yoghurt like blood.

\section{Case Report}

Was admitted at the age of 1 month and 3 weeks, as referral from nearby health 
centre, presenting with difficulty in breathing for 3 days, sudden onset associated with grunting and chest wall in drawing, was also accompanied with poor feeding, and irritability with no history of convulsion. At the heath centre the patient received Ceftriaxone injection, Hydrocortisone and oxygen therapy. On arrival the child had a Temperature of 36.4, pulse rate of 137 beats/minute, and respiratory rate of 64 breath/minute, saturating at $73 \%$ on room air and $95 \%$ on oxygen 2 litres via nasal prongs.

The baby was delivered at term with weight of $4 \mathrm{~kg}$, without any complication or prior history of admission and was firstborn to the parents with a positive history of hypertension in the maternal side (grandmother of a child).

Examination findings: Well-nourished, ill-looking, distressed on oxygen, mild pale, not cyanosed, not jaundiced, and had vitals $\mathrm{T}$ of $36.5^{\circ} \mathrm{C}$, pulse rate of $152 \mathrm{~B} / \mathrm{min}$, RR of $61 \mathrm{~B} / \mathrm{min}$.

Respiratory system examination had chest wall in drawing, with fine bilateral crackles, otherwise, on cardiovascular system, skin examination, abdominal examination and neurological examination were all normal.

Incidental finding: During sample collection the blood was noted to be strawberry yoghurt like, this prompted multiple venepuncture thinking the child had localized Puss collection, but even with change of area, the sample collected was the same (Figure 1).

Diagnosis and management: Had initial working diagnosis of severe pneumonia, hyperlipidaemia and differential diagnosis of chylomicronemia. The child was initiated on IV Ampiclox and Gentamicin, kept on oxygen therapy, and laboratory investigation were taken.

Investigation results: His initial full blood picture, the lab technician could not analyse the haemoglobin due to sample being too lipemic, otherwise this results showed leucocytosis of $21 \times 10^{9} / 1$, with neutrophil predominant of $49 \%$, haematocrit of $15.6 \%$, thrombocytosis of $547 \times 10^{9} / 1$ (Figure 3). After dilution of the sample with normal saline at 1:1 of which showed leukocyte count of $14.83 \times$ $10^{9} / \mathrm{l}$, haemoglobin of $19.3 \mathrm{~g} / \mathrm{dl}$, and platelets of $385 \times 10^{9} / \mathrm{l}$ haematocrit of $17.2 \%$

Her biochemistry profile showed a serum sodium level of $87 \mathrm{mmol} / \mathrm{l}$, potassium of $3.2 \mathrm{mmol} / \mathrm{l}$, urea of $3.1 \mathrm{mmol} / \mathrm{l}$, serum creatinine of $40 \mu \mathrm{mol} / \mathrm{l}$, triglyceride of $136 \mathrm{mmol} / \mathrm{l}(12,046 \mathrm{mg} / \mathrm{dl})$, total cholesterol of $43 \mathrm{mmol} / \mathrm{l}(1662 \mathrm{gm} / \mathrm{dl})$, HDL of $6 \mathrm{mmol} / \mathrm{l}(232 \mathrm{gm} / \mathrm{dl})$ and amylase of $20 \mathrm{U} / \mathrm{l}$. Having normal TSH of $2.43 \mu \mathrm{IU} / \mathrm{ml}$ and $\mathrm{T} 4$ of $125.8 \mathrm{ng} / \mathrm{ml}$, serology for HIV was negative and blood culture was negative as well.

Chest $\mathrm{x}$ ray had features suggestive of lobar pneumonia with increase in cardiac silhouette(X ray was supine) (Figure 2). After the investigations our working diagnosis was Severe Pneumonia, Electrolyte imbalance (hyponatremia and hypokalaemia) and Infantile Hypertriglyceridemia

Discharge and follow up: The child was to continue with antibiotics above, electrolyte correction of hyponatremia with $3 \%$ Sodium Chloride, as well as Potassium Chloride, and was started on Rosuvastatin $5 \mathrm{mg}$ orally daily dose.

$6^{\text {th }}$ day the child was off oxygen, she was discharged $8^{\text {th }}$ day after completing 
antibiotics with Rosuvastatin at the same dose, then scheduled to be seen as outpatient every month in our clinic, monitoring lipid profile in every visit.

The trend of lipid control as shown below (Table 1 and Figures 1-4):

Table 1. The trend of a child in response to rosuvastatin therapy.

\begin{tabular}{cccc}
\hline VISIT & TRIGLYCERIDE & TOTALCHOLESTEROL & HDL \\
\hline Initial & $136 \mathrm{mmo} / \mathrm{l}$ & $43 \mathrm{mmol} / \mathrm{l}$ & $6 \mathrm{mmol} / \mathrm{l}$ \\
$1^{\text {st }}$ visit & Not done & Not done & $6 \mathrm{mmo} / 1$ \\
$2^{\text {nd }}$ visit & $135.19 \mathrm{mmol} / 1$ & $44.6 \mathrm{mmol} / \mathrm{l}$ & $6 \mathrm{mmo} / 1$ \\
$3^{\text {rd }}$ visit & $133.92 \mathrm{mmol} / \mathrm{l}$ & $40 \mathrm{mmol} / \mathrm{l}$ & $4 \mathrm{mmol} / 1$ \\
$4^{\text {th }}$ visit(last visit) & $9.284 \mathrm{mmol} / 1$ & $6.84 \mathrm{mmol} / \mathrm{l}$ & $0.29 \mathrm{mmol} / 1$ \\
\hline
\end{tabular}

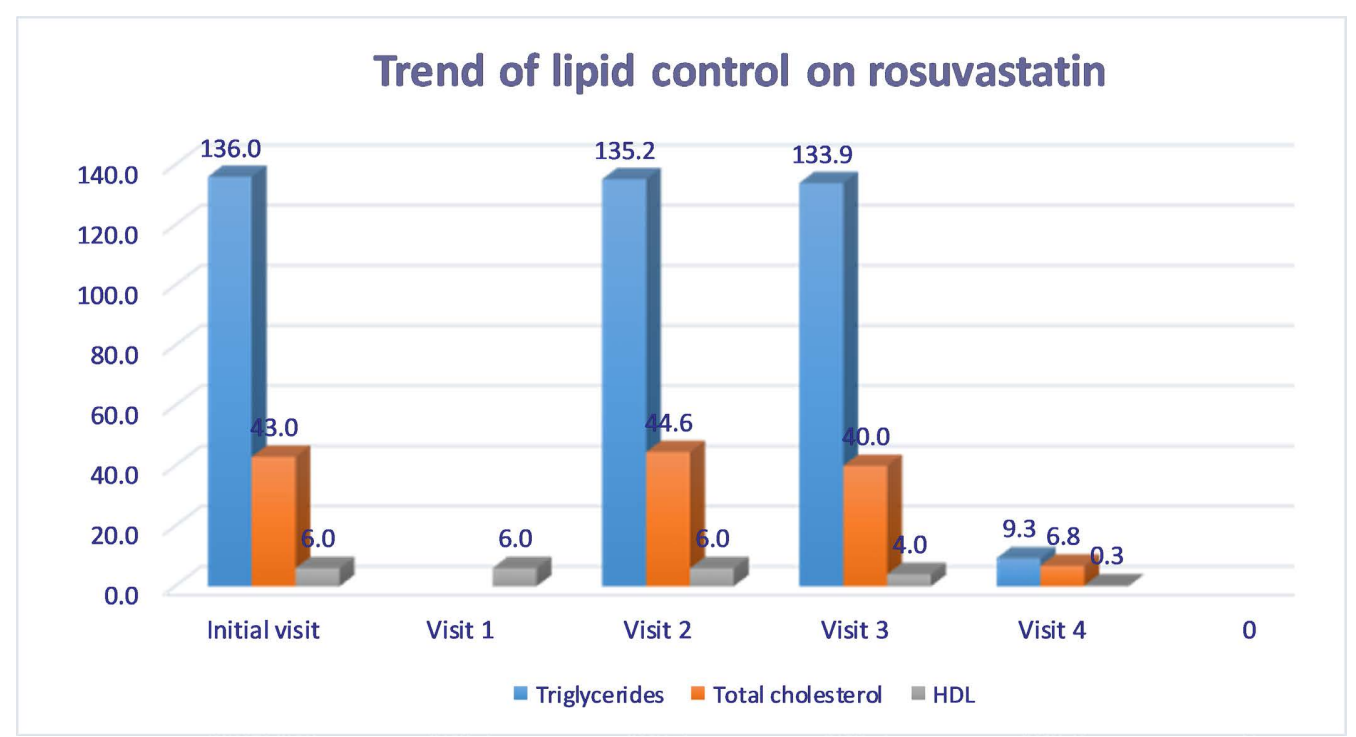

Figure 1. Trend of Lipid control on rosuvastatin.

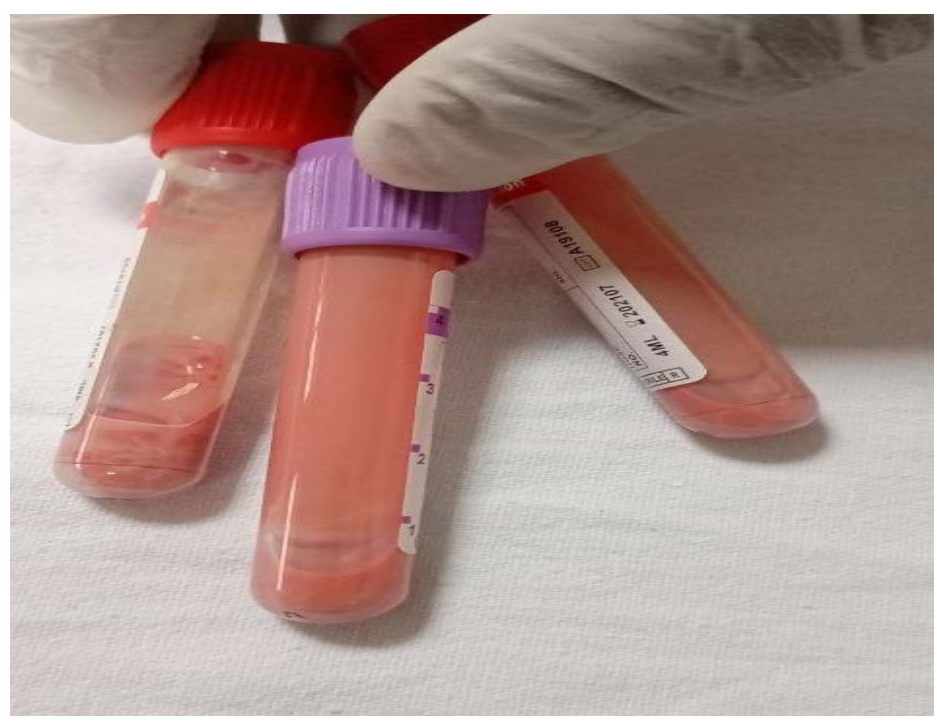

Figure 2. Sample obtained from a patient. 


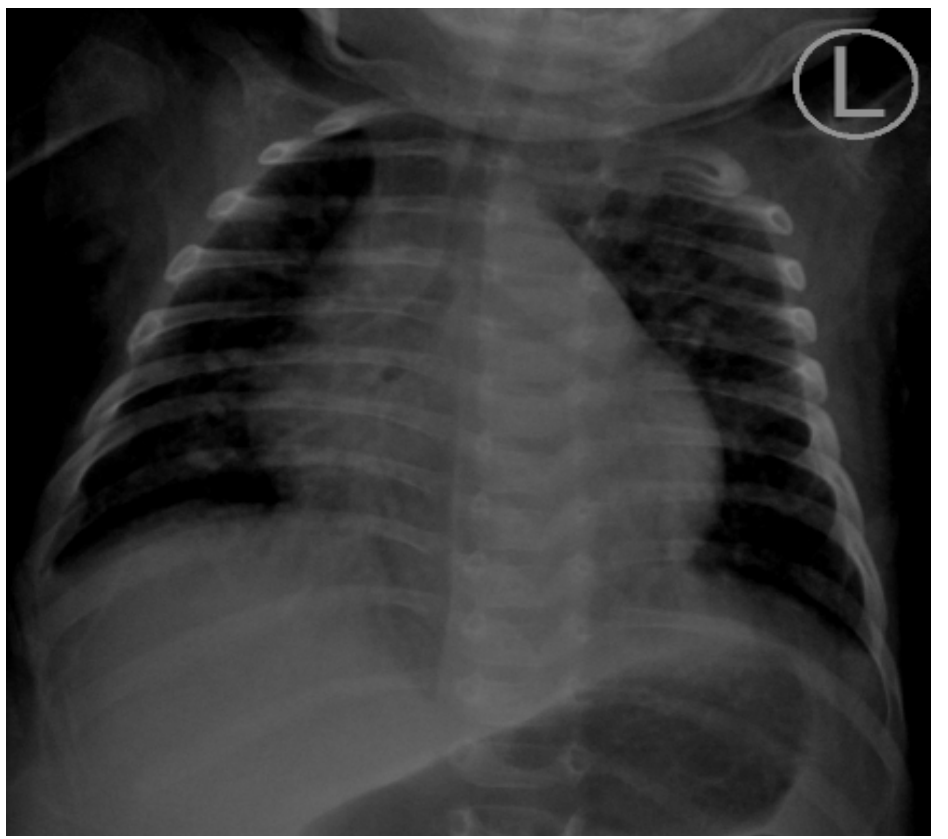

Figure 3. A supine $\mathrm{X}$ ray of the child showing the left upper lobe pneumonia with increase in cardiac silhouette.

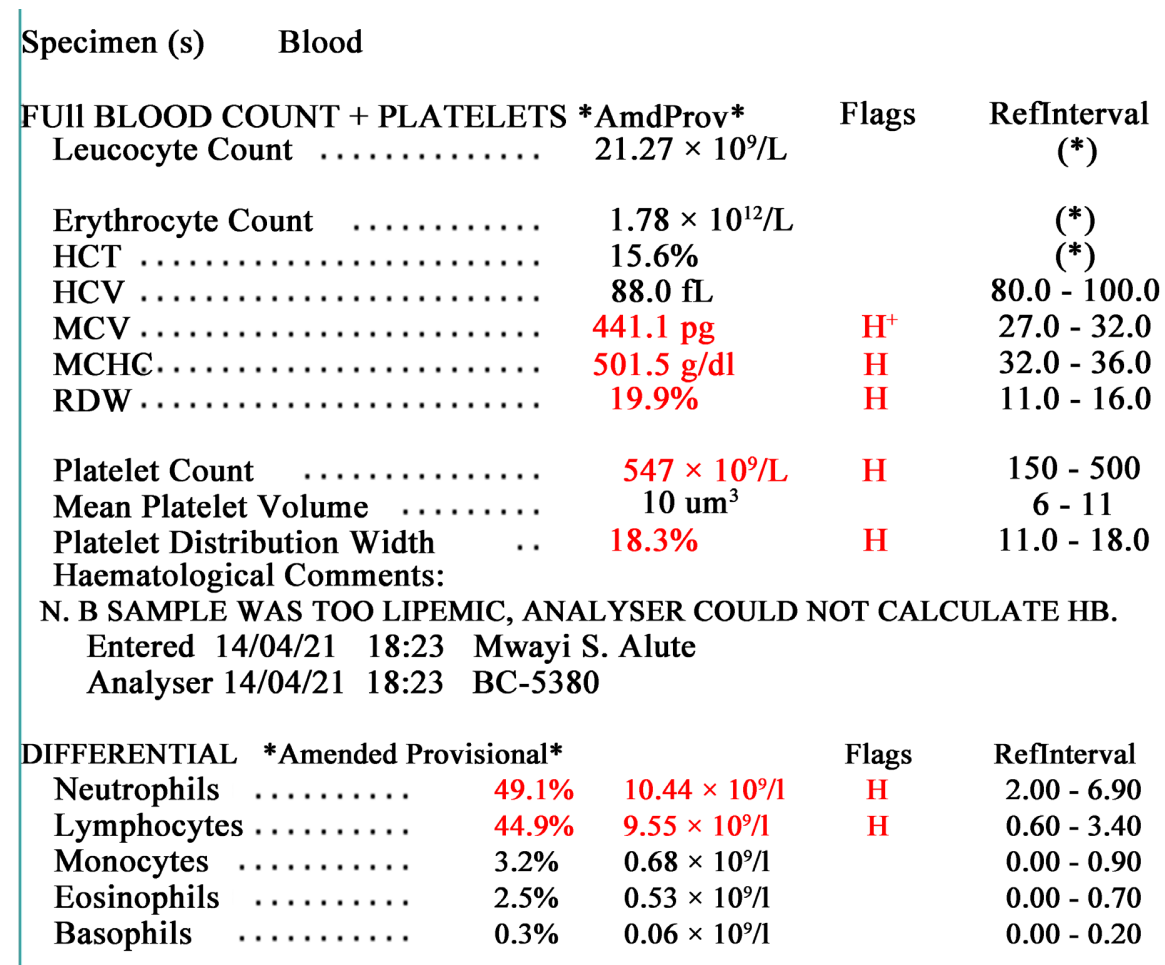

Figure 4. Initial full blood picture before dilution.

\section{Discussion}

WHO report shows increase in number of overweight children under five years by nearly $24 \%$ percent since 2000 . Due to association with increase in epidemic of obesity hyperlipidaemia is an increasing prevalent risk factor in children. Fa- 
milial hypocholesteraemia syndrome usually present in childhood, but few cases about $25 \%$ has been found to manifest during infancy [9]. There has been several cases reported from India, in very young children aged between less than a month and 2 month. Some presented with non-related clinical features such as bacterial infection with systemic complications such as acute renal failure and completely recovered. The diagnosis was clinical and genetic testing was not available [13]. This is similar to our patient who was diagnosed at 42 days of life and we also failed to do any advanced testing due financial constraints and limited resources. Most cases of lipid disorders are asymptomatic, even selective screening (i.e., screening only children with a positive family history) fail to identify a significant number of children with lipid disorders [14].

Paediatric lipid disorders often track into adulthood. Approximately $50 \%$ of children with abnormal serum lipoprotein values continue to have elevated lipid levels in adulthood [4] [15] [16] and [17]. Children with severely elevated lipid values consistent with familial hyperlipidaemia show stronger tracking to adulthood. Cumulative exposure to dyslipidaemia appears to be associated with cardiovascular risk later in life.

Pharmacological options for children with high triglyceride are limited, so most of interventions are non-pharmacological like diet modification, the use of fish oil, increased physical activity, and weight loss. Children with Triglyceride (TG) levels between $150 \mathrm{mg} / \mathrm{dl}(1.7 \mathrm{mmol} / \mathrm{l})$ and $399 \mathrm{mg} / \mathrm{dl}(4.5 \mathrm{mmol} / \mathrm{l})$ and a non-high-density lipoprotein cholesterol (non-HDL-C) $\geq 145 \mathrm{mg} / \mathrm{dl}(3.7 \mathrm{mmol} / \mathrm{l})$ may need pharmacology if other non-pharmacological treatment are unsuccessful. In our patient, diet and lifestyle modification were not feasible due to the young age so we opted for pharmacological intervention.

Although fibric acid derivatives e.g. gemfibrozil, fenofibrate are highly recommended in treatment of hypertriglyceridemia due to less side effect and being well tolerated in children, studies have shown triglyceride levels decreased with the use of fibrates, did not change when the statins were used, but found to increase when bile acid-binding resins were used e.g. cholestyramine [18]. Other studies also have suggested statins to be more effective with lowering the cholesterol than lowering triglyceride level [19] [20]. In our case, the child showed response to statin. The choice of medication was based on availability, family economic status, e.g. in out setting most common available lipid lowering drugs are statins, which prompted to be the first pharmacological option for the patient.

Lipid lowering drug (statins) and exclusive breast feeding dramatically improved lipid parameters to our patient without any reported adverse effect on follow-up. Although the cases of hypertriglyceridemia are rare, this also proves a role of statins in treatment of hypertriglyceridemia in low resource setting were the first line drugs like fibric derivatives are not available.

\section{Conclusion}

We report a case of infantile hypertriglyceridemia found accidentally during 
phlebotomy. Despite limited resource to evaluate further on primary cause of this condition as well as family's poor economic status to seek further medical evaluation outside the country, this case report raises awareness on how to deal with this condition. It also highlights the role of statins in the treatment of hypertriglyceridemia.

\section{Consent}

Verbal informed consent was obtained from the patient's mother for publication of this case report.

\section{Authors' Contributions}

MM, DNM, FM, AS conceptualised and prepared the manuscript PEM; PM, ERM, EK, AL, ZH, IM, NP, AI, LF, FM, RM, BM, LK and MJ reviewed the patient medical records. This manuscript has been read and approved by all authors.

\section{Conflicts of Interest}

The authors declare no conflicts of interest regarding the publication of this paper.

\section{References}

[1] Brunzell, J.D. (2007) Hypertriglyceridemia. New England Journal of Medicine, 357, 1009-1017. https://doi.org/10.1056/NEJMcp070061

[2] Schaefer, E., Leung, A., Kravarusic, J. and Stone, N. (2011) Management of Severe Hypertriglyceridemia in the Hospital: A Review. Journal of Hospital Medicine, 7, 431-438. https://doi.org/10.1002/jhm.995

[3] Expert Panel on Detection, Evaluation, and Treatment of High Blood Cholesterol in Adults (2001) Executive Summary of the Third Report of the National Cholesterol Education Program (NCEP) Expert Panel on Detection, Evaluation, and Treatment of High Blood Cholesterol in Adults (Adult Treatment Panel III). JAMA, 285, 2486-2497. https://doi.org/10.1001/jama.285.19.2486

[4] Expert Panel on Integrated Guidelines for Cardiovascular Health and Risk Reduction in Children and Adolescents (2011) Expert Panel on Integrated Guidelines for Cardiovascular Health and Risk Reduction in Children and Adolescents: Summary Report. Paediatrics, 128, S213-S256. https://doi.org/10.1542/peds.2009-2107C

[5] Miller, M., Stone, N., Ballantyne, C., Bittner, V., Criqui, M., et al. (2011) Triglycerides and Cardiovascular Disease. Circulation, 123, 2292-2333.

https://doi.org/10.1161/CIR.0b013e3182160726

[6] Ferranti, S.D. and Newburger, J.W. (2019) Dyslipidemia in Children: Management. UpToDate, Waltham.

[7] Shah, A. and Wilson, D. (2015) Primary Hypertriglyceridemia in Children and Adolescents. Journal of Clinical Lipidology, 9, 20-28.

https://doi.org/10.1016/j.jacl.2015.04.004

[8] Berglund, L., Brunzell, J., Goldberg, A., Goldberg, I., Sacks, F., et al. (2012) Evaluation and Treatment of Hypertriglyceridemia: An Endocrine Society Clinical Practice Guideline. Journal of Clinical Endocrinology \& Metabolism, 97, 2969-2989. 
https://doi.org/10.1210/jc.2011-3213

[9] Chaurasiya, O.S., Kumar, L. and Sethi, R.S. (2013) An Infant with Milky Blood: An Unusual but Treatable Case of Familial Hyperlipidemia. Indian Journal of Clinical Biochemistry, 28, 206-209. https://doi.org/10.1007/s12291-012-0285-9

[10] Perak, A.M., Ning, H., Kit, B.K., de Ferranti, S.D., Van Horn, L.V., Wilkins, J.T., et al. (2019) Trends in Levels of Lipids and Apolipoprotein B in US Youths Aged 6 to 19 Years, 1999-2016. JAMA, 321, 1895-1905.

https://doi.org/10.1001/jama.2019.4984

[11] Valaiyapathi, B., Sunil, B. and Ashraf, A.P. (2017) Approach to Hypertriglyceridemia in the Pediatric Population. Pediatrics in Review, 38, 424-434.

https://doi.org/10.1542/pir.2016-0138

[12] Nagaraja, S., Nathan, R. and El Sayed, A. (2017) Infant with Milky Blood: A Rare Case of Familial Chylomicronemia Presenting with Infantile Eruptive Xanthoma. Journal of Clinical \& Experimental Dermatology Research, 8, 4.

[13] Santamarina-Fojo, S. (1998) The Familial Chylomicronemia Syndrome. Endocrinology and Metabolism Clinics of North America, 27, 551-567. https://doi.org/10.1016/S0889-8529(05)70025-6

[14] US Preventive Services Task Force (2016) Screening for Lipid Disorders in Children and Adolescents: US Preventive Services Task Force Recommendation Statement. $J A M A, 316,625-633$. https://doi.org/10.1001/jama.2016.9852

[15] Feoli-Fonseca, J.C., Levy, E., Godard, M. and Lambert, M. (1998) Familial Lipoprotein Lipase Deficiency in Infancy: Clinical, Biochemical, and Molecular Study. The Journal of Pediatrics, 133, 417-423. https://doi.org/10.1016/S0022-3476(98)70280-X

[16] Haney, E.M., Huffman, L.H., Bougatsos, C., Freeman, M., Steiner, R.D. and Nelson, H.D. (2007) Screening and Treatment for Lipid Disorders in Children and Adolescents: Systematic Evidence Review for the US Preventive Services Task Force. Paediatrics, 120, e189-e214. https://doi.org/10.1542/peds.2006-1801

[17] Webber, L.S., Srinivasan, S.R., Wattigney, W.A. and Berenson, G.S. (1991) Tracking of Serum Lipids and Lipoproteins from Childhood to Adulthood. The Bogalusa Heart Study. American Journal of Epidemiology, 133, 884-889. https://doi.org/10.1093/oxfordjournals.aje.a115968

[18] Bao, W., Srinivasan, S.R., Wattigney, W.A., Bao, W. and Berenson, G.S. (1996) Usefulness of Childhood Low-Density Lipoprotein Cholesterol Level in Predicting Adult Dyslipidemia and Other Cardiovascular Risks. The Bogalusa Heart Study. Archives of Internal Medicine, 156, 1315-1320. https://doi.org/10.1001/archinte.1996.00440110083011

[19] Manlhiot, C., Larsson, P., Gurofsky, R.C., Smith, R.W., Fillingham, C., Clarizia, N.A., et al. (2009) Spectrum and Management of Hypertriglyceridemia among Children in Clinical Practice. Paediatrics, 123, 458-465. https://doi.org/10.1542/peds.2008-0367

[20] Ben-Avram, C.M., Ben-Zeev, O., Lee, T.D., Haaga, K., Shively, J.E., Goers, J., et al. (1986) Homology of Lipoprotein Lipase to Pancreatic Lipase. Proceedings of the National Academy of Sciences of the United States of America, 83, 4185-4189. https://doi.org/10.1073/pnas.83.12.4185 


\section{List of Abbreviations}

TG

triglyceride

LDH

low density lipoprotein

IV intravenous

TSH

thyroid stimulating hormone 